\title{
Correction to: Morbidity and costs of diverting ileostomy in transanal total mesorectal excision with primary anastomosis for rectal cancer
}

\author{
Jeroen C. Hol ${ }^{1}$ (I) Frederieke Bakker ${ }^{2} \cdot$ N. Tjarda van Heek ${ }^{1} \cdot$ Gabie M. de Jong ${ }^{1}$ • Flip M. Kruyt ${ }^{1}$. Colin Sietses ${ }^{1}$
}

Published online: 9 August 2021

(c) Springer Nature Switzerland AG 2021

Correction to: Techniques in Coloproctology https://doi.org/10.1007/s10151-021-02498-5

In this published online article Ref. 15 was incorrect and should have been "Rahbari NN et al. (2010) Definition and grading of anastomotic leakage following anterior resection of the rectum: a proposal by the International Study Group of Rectal Cancer. Surgery 147(3):339-351".

The original article has been corrected.

Publisher's Note Springer Nature remains neutral with regard to jurisdictional claims in published maps and institutional affiliations.

The original article can be found online at https://doi.org/10.1007/ s10151-021-02498-5.

Jeroen C. Hol

HolJ@zgv.nl

1 Department of Surgery, Gelderse Vallei Hospital, P.O. Box 9025, 6710 HN Ede, The Netherlands

2 Department of Finance, Gelderse Vallei Hospital, Ede, The Netherlands 